\title{
Use of bilevel positive airway pressure ventilatory support for pathological flail chest complicating multiple myeloma
}

\author{
J. Abisheganaden, C.B.E. Chee, Y.T. Wang
}

Use of bilevel positive airway pressure ventilatory support for pathological flail chest complicating multiple myeloma. J. Abisheganaden, C.B.E. Chee, Y.T. Wang. CERS Journals Ltd 1998.

ABSTRACT: Multiple myeloma is a common disease that universally involves the skeletal system. Although rib involvement may occur, the development of pathological flail chest is rare. We describe the treatment and course of this condition in an elderly female, and the use of the bilevel positive airway pressure (BiPAP) ventilatory system in providing pneumatic stabilization, while definitive chemotherapy was given to heal the pathological fractures.

Our experience with this patient suggests that, despite its dramatic clinical manifestation, the association of flail chest with multiple myeloma may not predict a poor prognosis. We have also found that pneumatic stabilization can be achieved by using the bilevel positive airway pressure ventilatory support through a tracheostomy.

Eur Respir J 1998; 12: 238-239.
Dept of Respiratory Medicine, Tan Tock Seng Hospital, Singapore.

Correspondence: C.B.E. Chee

Dept of Respiratory Medicine

Tan Tock Seng Hospital

Moulmein Road

Singapore 308433

Singapore

Fax: 652532884

Keywords: Flail chest, multiple myeloma, pathological fractures

Received: June 271997

Accepted after revision August 301997
Flail chest usually occurs secondary to traumatic multiple rib or sternal fractures. Patients with such injuries, who are in acute respiratory failure, have often required positive pressure ventilation and prolonged mechanical ventilation to achieve internal pneumatic stabilization of the chest wall $[1,2]$. This has been the traditional form of treatment. Surgical stabilization has also been suggested for severe flail chest, but its use has been questioned due to complications [3]. Other forms of achieving pneumatic stabilization have developed in recent years, including the use of mini-invasive [4] and noninvasive techniques [5]. These methods of achieving pneumatic stabilization are reliable and are now widely practised [4-6]. Hence, there has been a change in attitude and management practice over the years from the traditional invasive methods to the current less invasive or noninvasive techniques.

Although rib involvement may occur in multiple myeloma, the development of pathological flail chest is rare. We describe a female with multiple myeloma presenting as flail chest with respiratory failure, and the use of the bilevel positive airway pressure (BiPAP) ventilatory system in providing pneumatic stabilization, whilst definitive chemotherapy was given to heal her pathological fractures.

\section{Case report}

An 84 year old, previously healthy female first presented elsewhere with complaints of bone pains and progressive dyspnoea over a 6 month period. She was found to have flail chest due to multiple bilateral lower rib fractures. There was no history of trauma prior to these symptoms. She was in respiratory distress and required urgent intubation and ventilatory support. She underwent tracheostomy on day 20 of hospitalization. Her clinical course was further complicated by recurrent nosocomial pneumonia and failure to wean from the ventilator. She was subsequently transferred to our intensive care unit (ICU) for further management on day 68 .
At the ICU, paradoxical inward movements of the lower thoracic segments were evident bilaterally on inspiration. The patient was maintained on mechanical ventilation via the tracheostomy, which stabilized the flail segments. On pressure support ventilation of $15 \mathrm{cmH}_{2} \mathrm{O}$ and positive endexpiratory pressure (PEEP) of $5 \mathrm{cmH}_{2} \mathrm{O}$, the arterial $\mathrm{pH}$ was 7.48 , the arterial oxygen tension $\left(\mathrm{Pa}_{\mathrm{a}} \mathrm{O}_{2}\right) 10.4 \mathrm{kPa}(78$ $\mathrm{mmHg})$, and the arterial carbon dioxide tension $\left(\mathrm{Pa}_{\mathrm{a}} \mathrm{CO}_{2}\right)$ $6.4 \mathrm{kPa}(48 \mathrm{mmHg}$ ), whilst breathing $28 \%$ oxygen (fraction of inspired oxygen $\left.\left(F \mathrm{I}, \mathrm{O}_{2}\right) 0.28\right)$. Plain chest radiographs showed generalized osteopenia, with multiple pathological rib fractures bilaterally. Multiple myeloma was established on the basis of multiple lytic bone lesions and bone marrow biopsy, which showed increased plasma cells with $80 \%$ myeloma cells, and serum protein electrophoresis confirming an immunoglobulin A (IgA) myeloma (IgA $63.3 \mathrm{~g} \cdot \mathrm{L}^{-1}$, monoclonal band with anti-IgA and anti-kappa in serum samples). Urine was negative for Bence Jones proteins and there was no acute renal failure or renal impairment. The serum $\beta_{2}$-microglobulin level was elevat- ed at $9,732 \mu \mathrm{g} \cdot \mathrm{L}^{-1}$ (normal range (NR) 878-2,000 $\left.\mu \mathrm{g} \cdot \mathrm{L}^{-1}\right)$. There was an associated hypercalcaemia (serum calcium $2.85 \mathrm{mmol} \cdot \mathrm{dL}^{-1}$ ) and anaemia (blood haemoglobin $6.7 \mathrm{~g}$. $\mathrm{dL}^{-1}$ ). A blood film showed normocytic, normochronic red cells with moderate rouleaux formation. Erythrocyte sedimentation rate (ESR) was elevated at $>150 \mathrm{~mm} \cdot \mathrm{h}^{-1}$. A radiographic bone survey of all the major bones revealed, in addition to the multiple rib fractures, the presence of a sternal fracture. There were no fractures outside the chest.

The patient was taken off the ventilator on day 75 (a week after arrival at the ICU) and started on BiPAP support (initial inspiratory positive airway pressure (IPAP) of 16 $\mathrm{cmH}_{2} \mathrm{O}$, and expiratory positive airway pressure (EPAP) of $5 \mathrm{cmH}_{2} \mathrm{O}$ ) via the tracheostomy. Monitoring of the rib cage and abdominal movements demonstrated that the asynchronous paradoxical movements were abolish- ed by BiPAP ventilatory support (fig. 1). At this stage, att-empts to wean the patient caused the return of paradoxical move- 


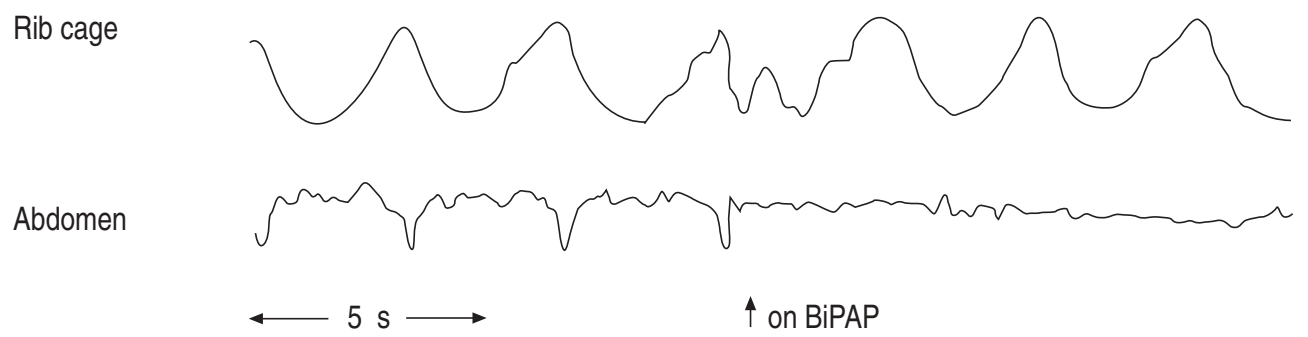

Fig. 1. - Representative simultaneous tracings of rib cage and abdominal excursion versus time measured by Respecters bands before and while on bilevel positive airway pressure (BiPAP) ventilatory support of $16 / 8 \mathrm{cmH}_{2} \mathrm{O}$. Upward movement of the rib cage trace signifies inspiration. The paradoxical movements were abolished whilst on the ventilatory support.

ments and respiratory distress. She was supported on BiPAP in the high dependency ward for 2 months, during which period the myeloma was treated with three 4 day courses of melphalan-prednisolone chemotherapy given every 3 weeks for the rib fractures to heal. The BiPAP support was gradually tailed-off as her pathological fractures healed. At IPAP $8 \mathrm{cmH}_{2} \mathrm{O}$ and EPAP $5 \mathrm{cmH}_{2} \mathrm{O}$ and breathing room air, the $\mathrm{pH}$ was $7.47, \mathrm{~Pa}_{\mathrm{a}} \mathrm{O}_{2} 10.5 \mathrm{kPa}(79$ $\mathrm{mmHg})$ and $P \mathrm{a}, \mathrm{CO}_{2} 5.5 \mathrm{kPa}(41 \mathrm{mmHg})$.

The condition of the patient improved, as evidenced by callus formation on serial chest radiographs, improvements in her respiratory status, and a marked decrease in the $\operatorname{IgA}$ levels to less than half the original value. On day 128 , she was weaned off BiPAP support and was able to breathe unaided. On breathing room air, the $\mathrm{pH}$ was 7.48, the $\mathrm{Pa}, \mathrm{O}_{2} 8.7 \mathrm{kPa}(65 \mathrm{mmHg})$ and the $P \mathrm{a}, \mathrm{CO}_{2} 5.3 \mathrm{kPa}(40$ $\mathrm{mmHg}$ ). The flail segments healed and paradoxical motion was minimal. She was discharged on day 158,3 months after arrival at our hospital, with further courses of chemotherapy scheduled. She was well on discharge.

\section{Discussion}

Although skeletal involvement is common in multiple myeloma, spontaneous flail chest resulting from rib fractures is extremely rare. The occurrence of such a complication in a patient with multiple myeloma prompted this report, and a review of the literature. There have been only six previous reports of patients with pathological flail chest complicating myeloma [7-11]. The uniqueness of this patient was the fact that the myeloma, which was previously undiagnosed, first manifested as flail chest with respiratory failure.

Mild flail chest generally requires only supportive therapy. However, positive airway pressure, provided by continuous positive pressure ventilation, continuous positive airway pressure (CPAP), or a combination of intermittent mandatory ventilation and PEEP is necessary in patients with severe flail chest in order to diminish the paradoxical movements of the chest by internal stabilization [1, 2]. However, what was especially unique in this patient was the early use of BiPAP support, delivered through the tracheostomy, within a week of her transfer to the ICU, and its ability to provide a means of ventilatory support while definitive chemotherapy was given for her fractures to heal.

The BiPAP ventilatory support system is a light-weight, portable support ventilator developed for noninvasive use. It is based on a standard positive airway pressure, highflow generator system and cycles in response to the patient's respiratory flow, between preset levels of IPAP and EPAP. We believe that this is the first such case of the use of BiPAP ventilation through a tracheostomy for patho- logical flail chest complicating multiple myeloma. The BiPAP was successful in reducing the work of breathing for the patient, whilst at the same time airway suctioning was possible through the tracheostomy. The patient was weaned by gradually diminishing the IPAP and EPAP levels, and, later, by taking her off the portable ventilator for longer and longer periods. All this was done out of the ICU setting, freeing up the ICU resources.

GREGORETTI et al. [4] have recently reported the use of pressure control ventilation delivered through a minitracheotomic cannula as an alternative to conventional tracheal ventilation to treat severe flail chest. They found that this method could achieve a suitable gas exchange and provide stabilization in a flail chest condition, at the same time reducing the side-effects of tracheal intubation.

Our experience with this patient suggests that, despite its dramatic clinical manifestation, the association of flail chest with multiple myeloma may not predict a poor prognosis. In such cases, vigorous specific as well as supportive therapy is mandatory. We have also found that pneumatic stabilization can be achieved by using the bilevel positive airway pressure ventilatory support through a tracheostomy.

\section{References}

1. Cullen P, Modell JH, Kirby RR. Treatment of flail chest. Arch Surg 1975; 110: 1099-1103.

2. Lewis F, Thomas AN, Schlobolm RM. Control of respiratory therapy in flail chest. Ann Thorac Surg 1975; 20: 170-176.

3. Debesse BL. Current treatment of flail chest. Presse Med 1989; 16: 559-560.

4. Gregoretti C, Foti G, Beltrame F, et al. Pressure control ventilation and minitracheotomy in treating severe flail chest trauma. Intensive Care Med 1995; 21: 1054-1056.

5. Branson RD, Hurst JM. Mask CPAP: state of the art. Respir Care 1985; 30: 846-857.

6. Iapichino G, Gavazzeni V, Mascheroni D, Bordone G, Solca M. Combined use of mask CPAP and minitracheotomy as an alternative to endotracheal intubation. Intensive Care Med 1991; 17: 57-59.

7. Mansouri A. Flail chest and multiple myeloma (Letter). $J$ Am Med Assoc 1980; 243: 1036.

8. Fleegler B, Fogarty C, Owens G, Cohen E, Cassileth PA. Pathologic flail chest complicating multiple myeloma. Arch Intern Med 1980; 140: 414-415.

9. Rammohan G, Karbowitz SR. Spontaneous flail chest in multiple myeloma: successful recovery. NY State J Med 1981; 81: 235-236.

10. Clinicopathologic conference. Multiple myeloma. Am J Med 1964; 36: 121-134.

11. Kanarek KJ, Zwi S. Spontaneous flail chest. S Afr Med J 1971; 45: 1262-1265. 